\title{
EquiLIBRIUM
}

Quarterly Journal of Economics and Economic Policy

2016 VOLUME 11 ISSUE 1, March

p-ISSN 1689-765X, e-ISSN 2353-3293

www.economic-policy.pl

Próchniak, M., \& Witkowski, B. (2016). On the Use of Panel Stationarity Tests in Convergence Analysis: Empirical Evidence for the EU Countries. Equilibrium. Quarterly Journal of Economics and Economic Policy, 11(1), pp. 77-96, DOI: http://dx.doi.org/10.12775/ EQUIL.2016.004

\author{
Mariusz Próchniak, Bartosz Witkowski * \\ Warsaw School of Economics, Poland
}

\section{On the Use of Panel Stationarity Tests in Convergence Analysis: Empirical Evidence for the EU Countries **}

JEL Classification: $C 22 ; C 23 ; O 47 ; O 52$

Keywords: economic growth; convergence; catching up; stationarity; ADF test

\begin{abstract}
The study examines the concept of stochastic convergence in the EU28 countries over the 1994-2013 period. The convergence of individual countries' GDP per capita towards the EU28 average per capita income level and the pairwise convergence between the GDP of individual countries are both analyzed. Additionally, we introduce our own concept of conditional stochastic convergence which is based on adjusted GDP per capita series in order to account for the impact of other growth factors on GDP. The analysis is based on time series techniques. To assess stationarity, ADF tests are used. The study shows that the process of stochastic convergence in the EU countries is not as widespread as the cross-sectional studies on $\beta$ or $\sigma$ convergence indicate. Even if we extend the analysis to examine conditional stochastic convergence, the number of converging economies or pairs of countries rises, but not as much as it could be expected from the cross-sectional studies.
\end{abstract}

(C) Copyright Institute of Economic Research

Date of submission: March 17, 2015; date of acceptance: December 2, 2015

* Contact: mproch@sgh.waw.pl, bwitko@sgh.waw.pl, Szkoła Główna Handlowa w Warszawie, Al. Niepodległości 162, 02-554 Warszawa, Poland

** The research project has been financed by the National Science Centre in Poland (decision number DEC-2012/07/B/HS4/00367). 


\section{Introduction}

Ever since the Sala-i-Martin's and Barro's and Mankiw et al.'s well recognized studies (see e.g. Barro \& Sala-i-Martin, 1990, 2003; Mankiw et al., 1992), the issue of income-level convergence has gained huge popularity in the literature. The two most common concepts of convergence were proposed: $\beta$ convergence (when less developed countries grow faster than more developed ones) and $\sigma$ convergence (when income differences between economies decrease over time). A number of methods have been developed which enable for empirical verification whether the process of convergence is actually taking place, starting with the cross-section based Barro regression as the most popular technique that enables for the verification of the $\beta$ convergence hypothesis.

However, parallel to the classical definitions and methods of analysis, the concept of stochastic convergence has been theoretically and empirically developed in the literature. With the gradual development of panel data based stationarity tests, the range of tools available for empirical analysis has rapidly increased. and there are currently numerous tools that allow to verify empirically the existence of so called stochastic convergence. Its idea, dating from the early nineties and described fully in such papers as Bernard \& Durlauf (1995), is to define convergence on the basis of time series rather than - as in the case of the most popular $\beta$ convergence - cross section, though recently both concepts have been seriously developed due to the popularity of panel data studies. Contrary to the $\beta$-convergence-type thinking, in which it is the current situation and the recent influence of the lagged GDP on current growth, in the case of stochastic convergence it is the expected value of future differences between the GDP levels in different countries that are taken into account. In the case when there is stochastic convergence, the basic concept is to expect the difference between the level of development to be zero in the infinite time horizon.

All the concepts of convergence are interrelated. However, they should be tested separately and treated as complementary rather than substitutive. Since they require different estimation methods, the results need not be the same. For example, as Bernard \& Durlauf (1996) indicate, time series tests are based on a stricter notion of convergence than the cross-section tests; hence, under certain assumptions, the cross-section tests can spuriously reject a no-convergence hypothesis while time-series tests do not.

Our analysis covers the 28 European Union countries (EU28) and the 1994-2013 period. We examine the stochastic convergence of the individual countries toward the EU28 average per capita GDP level as well as between the pairs of the individual countries (by examining 378 pairs). 
A new element of our analysis is the extension of the classical concept of stochastic convergence. The stochastic convergence, implying that GDP differences against the group average or between the individual countries diminish over time, is called the absolute stochastic convergence. However, as in the case of the $\beta$ convergence, we extend this approach for conditional convergence because there are many factors of economic growth and it is difficult to assume that all the countries tend to the same steady state. Namely, we adjust the GDP time series by eliminating the impact of selected economic growth determinants to account for the fact that the countries are not homogenous in terms of economic growth factors. The analysis of stochastic convergence on the adjusted-GDP time series is the core of the concept of stochastic conditional convergence. ADF tests are used to test for stationarity of the series of differences between the GDP of a considered country and mean GDP of the considered group of countries (as in Bernard \& Durlauf, 1995), however, ADF tests are also used in the Pesaran's (2007) procedure of testing stationarity of the series of GDP gaps in each possible pair of countries from the considered group. The GDP series might, though, not converge due to serious diverging trends caused by different values of GDP growth factors in different countries. That is why we follow by checking the existence of conditional stochastic convergence by first estimating a panel-data-based $\beta$ convergence equation. We use the estimates of parameters on the growth factors to eliminate their influence from the GDP growths of different countries and follow by reconstructing the GDP level series, applying the ceteris paribus rule with regard to the considered growth factors. We then repeat the above described procedures of Bernard \& Durlauf and Pesaran with the series from which the influence of the growth factors has been eliminated.

There are a lot of empirical studies on cross sectional $\beta$ and $\sigma$ convergence. Abreu et al. (2005) found an enormous number of 1650 empirical articles on convergence. Matkowski et al. (2013) present a wide review of empirical studies on convergence for the EU countries. The studies in which stochastic convergence is analyzed appear less frequently in the literature, although they are by no means scarce.

For instance, Bernard \& Durlauf (1995) reject the existence of stochastic convergence in the whole group of the 15 OECD countries over the 1900-1987 period, but find substantial evidence for common trends (smaller samples of European countries did not converged either). Pesaran (2007) examines both the output and growth stochastic convergence among the world countries from 1951 to 2000 (the number of countries for some subperiods exceeds 100) concluding that there is no output convergence and the findings of convergence clubs in the literature might be spurious, but 
there is significant evidence of growth convergence. Other studies in which stochastic convergence (in a different operational form) was tested with the use of time-series techniques for various groups of countries include: $\mathrm{Cu}$ ñado \& Pérez de Gracia (2006) for African countries; Christopoulos \& León-Ledesma (2008) for the OECD countries; Cunado (2011) for the OPEC countries; Evans \& Kim (2011) for the Asian countries. Stochastic convergence was also examined in the regional context by: Kane (2001) for the U.S. regions; Lau (2010) for Chinese regions; and Le Pen (2011) for European regions. However, we have not seen in the literature the study in which the stochastic convergence for the whole EU28 group was examined in the way adopted here.

The paper is composed of four sections. The next section discusses the research methodology by presenting the concept of absolute and conditional stochastic convergence. The further section describes and discusses the results. The last section concludes the paper.

\section{Method of the Research}

Let $\ln G D P_{i, t}$ represent the logarithm of the GDP of country $i$ in period (year) $t$. We can then state that countries $i$ and $j$ converge stochastically ${ }^{1}$ if

$$
\lim _{k \rightarrow \infty}\left(\ln G D P_{i, t+k}-\ln G D P_{j, t+k} \mid I_{t}\right)=0,
$$

where $I_{t}$ represents the set of information available at time $t$, and the $\ln G D P_{i, t}$ throughout the paper is the natural logarithm of the ith country's GDP per capita (at purchasing power parity at constant US\$) in year $t$. The econometric way to see and test for the above is to notice that for the formula (1) to be fulfilled, a co-integrating vector $[1,-1]$ is required for the series $\ln G D P_{i, t}$ and $\ln G D P_{j, t}$. Suppose we are testing for convergence in the bivariate case of countries $i$ and $j$. That requires computing the gap series

$$
d G D P_{i j, t}=\ln G D P_{i, t}-\ln G D P_{j, t}
$$

${ }^{1}$ This definition is quite strict - Bernard \& Durlauf (1995), among others, also define a more liberal concept of common trend in bivariate or multivariate output, whose special case is the exact stochastic convergence. That requires replacing formula (1) with $\lim _{k \rightarrow \infty}\left(\ln G D P_{i, t+k}-\gamma \ln G D P_{j, t+k} \mid I_{t}\right)=0$. 
and testing for the stationarity of the $d G D P_{i j, t}$ series. ${ }^{2}$ Usually a variation of the ADF test would be used here, though Pesaran (2007) among others discusses also the KPSS-type tests as the power of ADF tests is questionable especially in the case of short series.

Should a group of - potentially - converging countries include more than two of them, two main options are available. Again following Bernard $\&$ Durlauf (1995) and most other research, one can test for convergence replacing the series of gaps between two countries output (2) with the series of gap between the $\ln G D P_{i, t}$ and its mean in a group of considered countries:

$$
d G D P_{i, t}=\ln G D P_{i, t}-\overline{\ln G D P}_{t},
$$

while the definition of stochastic convergence (1) would now be replaced with

$$
\lim _{k \rightarrow \infty}\left(\ln G D P_{i, t+k}-\overline{\operatorname{lnGDP}}_{t+k} \mid I_{t}\right)=0 .
$$

Pesaran (2007), however, points out the weakness of such a procedure and suggests a modified approach for the multivariate case. Its core in a group of $N$ countries is to check for stationarity of gap series defined as (2) for every possible pair of countries, that is for all the $N(N-1) / 2$ nonredundant cases. With the support of simulation studies, Pesaran argues for the efficiency of such a procedure and points out that if we apply the ADFtype tests of stationarity and assume certain level of significance $\alpha$, then if there is no convergence in the considered group, the rejection rate of the null hypothesis shall asymptotically tend to $\alpha$.

In this paper, we analyze the convergence of the group of the $28 \mathrm{EU}$ countries. The annual series of data start in 1994 and finish in 2013. Both the convergence to mean (as in (4), $i=1, \ldots, 28)$ and pairwise convergence (as in $(1), i, j=1, \ldots, 28)$ are analyzed. An ADF test is used with a single lag in each of the equations (we check that it is sufficient to eliminate the - in most cases slight - autocorrelation of $d G D P_{i j, t}$ and $d G D P_{i, t}$ respectively).

In the analyses of the $\beta$ convergence it is common to consider two types of it: the absolute and the conditional convergence. We suggest a similar approach in the field of stochastic convergence. There is a possibility that the series of $\ln G D P$ of certain country would not be converging due to

\footnotetext{
${ }^{2}$ In the case of common trends instead of the strict stochastic convergence, the test of trend-stationarity would be used instead and the co-integrating vector would need to be $[1,-\gamma]$.
} 
reasons other than autonomous. Namely: the flow of physical as well as human capital and technical thought would make it converge if it were not for the values of certain growth factors. As an example, let us suppose that the government of the country does everything it could in order to convert it in an autarchy, which naturally also limits the flow of technical thought. Let us further suppose that the government consumption is excessively high. It might be that unless these two factors slowed down the convergence process, the country would be heading towards the rest of the considered group, but as the two abovementioned growth factors play a highly negative role, the convergence of the pure series of $\ln G D P$ would not be observed. In order to overcome this issue, we propose analyzing the convergence of the series of adjusted $\ln G D P$. The proper correction that should be applied consists in eliminating the influence of the (non-homogeneous across countries) growth factors that distort the series. The procedure that we suggest is the following.

As the first step, we estimate a Barro-type model of GDP convergence as in Próchniak \& Witkowski (2013). The functional form of the estimated model is

$$
\Delta \ln G D P_{i t}=\alpha_{i}+\beta_{0} \ln G D P_{i, t-1}+x_{i t}^{\prime} \beta+\varepsilon_{i t},
$$

where $\alpha_{i}$ is the individual effect of $i$-th country, $\beta_{0}$ is the $\beta$-convergence parameter, $x_{i t}$ is the vector of the growth factors while $\beta$ is the vector that covers their influence on the GDP growth and finally $\varepsilon_{i t}$ represents the error term. The model itself is estimated and cross-sectional data are used, while a minor transformation is applied in the case of panel-data-based analysis (Próchniak \& Witkowski, 2014).

In this paper, the convergence of the EU28 group is considered in the 1994-2013 period. We thus have a panel with annual observations and the Blundell and Bond's system GMM estimator is used (Blundell \& Bond, 1998). Given the economic sense and data availability, the following variables are considered as economic growth determinants

- log of lagged GDP per capita (at purchasing power parity at constant US\$);

- investment (\% of GDP) - inv;

- general government consumption expenditure (\% of GDP) - gov_cons;

- openness rate ((exports + imports)/GDP) - open;

- current account balance (\% of GDP) - cab;

- inflation (annual \%) - infl;

- $\log$ of fertility rate (births per woman) - fert;

- population growth (annual \%) - pop_gr; 
- population ages 15-64 (\% of total) - pop_15_64;

- $\log$ of life expectancy at birth (years) - life;

- $\log$ of population, total - pop.

The last two variables (life and pop) are further eliminated in the stepwise regression procedure and they are not included in the final model.

The aim of this study is not to explain fully the sources of economic growth. Instead, the aim is to include in the GDP growth regression the factors that from the theoretical and empirical point of view are the most important determinants of both the pace of economic growth and the steady-states to which the individual countries are tending. The choice of control variables is based on our earlier studies on $\beta$ convergence and economic growth determinants. The set of variables includes typical and significant factors of economic growth, but of course not all the possible time series. The variables that represent population aspects - mainly responsible for human capital - (fert, pop_gr, pop_15_64, life, pop) are treated as exogenous, while all the remaining are allowed to be endogeneous, which is based on the economic knowledge and/or intuition in this manner: the variables assumed to be exogeneous are not likely to be dependent on the economic growth in short time horizon themselves, which is why we do not decrease efficiency of the estimator by allowing their endogeneity.

Once the model (5) is estimated, the estimates $\hat{\beta}$ are known. Now in the second step, the vector of $\Delta \ln G D P_{i t}$ for each $i=1, \ldots, N$ can be modified so as to constitute

$$
\Delta \widetilde{\operatorname{nGD} P} P_{l t}=\Delta \operatorname{lnGDP_{it}}-\left(x_{i t}^{\prime}-\bar{x}_{. t}^{\prime}\right) \hat{\beta},
$$

where the $\bar{x}_{. t}$ represent average values of all the considered growth factors throughout the sample in period $t$.

In the third step, the modified $\ln G D P$ series are created for each of the considered countries. In each of the cases, the modified series is defined as

$$
\widetilde{\ln G D} P_{i t}=\left\{\begin{array}{cc}
\ln G D P_{i t} & t=1 \\
\widetilde{\ln G D} P_{i, t-1}+\Delta \ln G D P_{i t} & t=2, \ldots, T .
\end{array}\right.
$$

Naturally, should a group of countries be homogeneous in the sense of the values of growth factors across countries $x_{i t}$ in each of the periods $t=1, \ldots, T$, the properties of the $\overparen{\operatorname{nGD} P} P_{i t}$ would be the same as of the $\ln G D P_{i t}$. However, they are obviously not, thus while the absolute stochastic convergence (1) or (4) might not take place, the relative convergence, defined as 


$$
\lim _{k \rightarrow \infty}\left(\ln \widetilde{G D P_{l, t+k}}-\ln \widetilde{G D P_{j, t+k}} \mid I_{t}\right)=0
$$

if Bernard and Durlauf's type of procedure is applied or as

$$
\lim _{k \rightarrow \infty}\left(\ln {\widetilde{G D P_{l, t+k}}}-{\overline{\ln \overline{G D P}_{t+k}}}_{t} \mid I_{t}\right)=0
$$

if Pesaran's type approach is applied might occur.

As a last step we apply the same ADF test with a single lag in order to test for stationarity of the series of

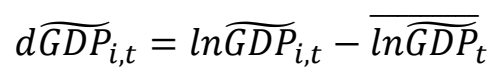

in the Bernard and Durlauf's type of approach or

$$
d \widetilde{G D P}_{i j, t}=\ln \widetilde{G D P}_{i, t}-\ln \widetilde{G D P}_{j, t}
$$

in the Pesaran's type of approach. Rejecting the null hypothesis of nonstationarity of the series (10) or (11) would suggest that the considered economies converge stochastically in the conditional sense, while the stronger case of rejection the non-stationarity hypothesis of (2) or (3) would suggest the existence of absolute stochastic convergence. The empirical results of the above described procedures are given in the next section.

\section{Results}

The results of testing the stochastic absolute convergence hypothesis are presented in Tables 1 and 2. Table 1 refers to the convergence toward the EU28 average per capita income level while Table 2 concerns the pair-wise catching-up process.

Table 1. Results of stochastic absolute convergence toward the EU28 income level

\begin{tabular}{l|l}
\hline Converging countries & $\boldsymbol{p}$-value \\
\hline Cyprus & 0.1 \\
\hline
\end{tabular}

The table includes only the countries that exhibited convergence, i.e those for which GDP deviations against the EU28 average were stationary. ADF test with a single lag and a constant is used.

Source: own calculations. 
It turns out that the studied countries did not reveal - in general - very strong stochastic convergence tendencies. Table 1 shows that Cyprus is the only country that converged toward the EU28 average income level. For the other 27 countries, the null hypothesis in the stationarity test could not be rejected at the $10 \%$ significance level. In the case of Cyprus, the null hypothesis was rejected, meaning that the deviations of Cyprus's GDP from the average EU28 per capita income are stationary meaning the existence of convergence.

The confirmation of stochastic absolute convergence for Cyprus is very difficult to be unambiguously explained. To some extent, it may result from the fact that Cyprus is a small island country. Its economy is influenced by a lot of external factors and it exhibits stochastic convergence towards the average GDP per capita in the EU28 group. However, we also cannot exclude that this is a spurious result - the more so that some other similar countries, like Malta, did not exhibit this type of convergence.

These findings shed new light on the catching-up process of the EU countries, and should be treated as complementary to the other studies on convergence, based on different concepts and methods. Namely, while most cross-sectional studies on $\beta$ and $\sigma$ convergence confirm the existence of the catching-up process inside the enlarged European Union, in the case of stochastic convergence the results are less evident. This difference constitutes the value added of this analysis and can be explained as follows.

First, the lack of stochastic convergence toward the EU28 average income may result from the fact that the EU group's average GDP is created by a number of countries which are homogenous in the long-run perspective, but in the short run they may reveal different economic growth paths. Hence, due to a differentiated influence of EU members on the current pace of economic growth of the whole group, the average GDP per capita for the whole group does not match well that for the individual countries.

Second, it is also likely that the stronger catching-up tendencies would be observed towards only Western Europe rather than the EU28 as a whole. This hypothesis would require testing the EU15 per capita income level or the weighted average EU28 per capita GDP as the reference point (in the latter case, the impact of the CEE countries on the average would be much smaller and in the case of some small CEE countries - like the Baltics, Cyprus or Malta - even negligible).

Third, the lack of stochastic convergence may result from the fact that the individual countries tend toward the best performers (like Luxembourg) or the biggest economies (like Germany, France, or UK) and not toward the EU28 average. To verify this hypothesis, the pair-wise convergence should be tested, which will be done in the next step of the analysis. 
Fourth, it is likely that the lack of stochastic convergence results from the fact that the convergence is analyzed in absolute terms (on the basis of non-adjusted GDP per capita time series). In contrast, it may be expected that the catching-up process occurs conditionally with regard to different steady-states to which the individual countries are tending. This view will be assessed in the next steps, when the conditional stochastic convergence is examined.

The results of pair-wise stochastic absolute convergence are reported in Table 2. Table 2 lists the pairs of countries for which the stochastic convergence has been confirmed. The results are symmetric, meaning that if country A is converging towards country B, country B is also converging toward country A. The results of pair-wise convergence need not be similar to those towards the EU28 as already described; hence, it is worth to analyze both of them.

Table 2. Results of pair-wise stochastic absolute convergence

\begin{tabular}{|c|c|c|}
\hline No. & Country & $\begin{array}{l}\text { Countries with which a given country } \\
\text { is converging }\end{array}$ \\
\hline 1 & Austria & Germany, Ireland, Malta \\
\hline 2 & Belgium & Ireland \\
\hline 3 & Bulgaria & Estonia, Latvia, Lithuania, Poland, Slovakia \\
\hline 4 & Croatia & Germany, Hungary, Slovenia \\
\hline 5 & Cyprus & 年 \\
\hline 6 & Czech Republic & - \\
\hline 7 & Denmark & Ireland \\
\hline 8 & Estonia & Bulgaria \\
\hline 9 & Finland & France, Germany, Ireland \\
\hline 10 & France & Finland, Ireland, Spain, UK \\
\hline 11 & Germany & Austria, Croatia, Finland, Ireland, Malta, Sweden \\
\hline 12 & Greece & - \\
\hline 13 & Hungary & Croatia, Ireland \\
\hline 14 & Ireland & $\begin{array}{l}\text { Austria, Belgium, Denmark, Finland, France, Germa- } \\
\text { ny, Hungary, Italy, Luxembourg, Malta, Netherlands, } \\
\text { Portugal, Spain, Sweden, UK }\end{array}$ \\
\hline 15 & Italy & Ireland \\
\hline 16 & Latvia & Bulgaria \\
\hline 17 & Lithuania & Bulgaria \\
\hline 18 & Luxembourg & Ireland \\
\hline 19 & Malta & Austria, Germany, Ireland \\
\hline 20 & Netherlands & Ireland \\
\hline
\end{tabular}


Table 2 continued

\begin{tabular}{lll} 
No. & Country & \multicolumn{1}{c}{$\begin{array}{c}\text { Countries with which a given country } \\
\text { is converging }\end{array}$} \\
\hline 21 & Poland & Bulgaria \\
\hline 22 & Portugal & Ireland \\
\hline 23 & Romania & - \\
\hline 24 & Slovakia & Bulgaria \\
\hline 25 & Slovenia & Croatia \\
\hline 26 & Spain & France, Ireland \\
\hline 27 & Sweden & Germany, Ireland \\
\hline 28 & UK & France, Ireland \\
\hline
\end{tabular}

$p$-value of 0.1 is assumed in stationarity tests. ADF test with a single lag and a constant is used.

Source: own calculations.

In the studied group of countries, the pair-wise convergence, like the convergence toward the EU28, is not very strong, either. Only $8.2 \%$ of the total number of pairs of countries turned out to be statistically significant at the $10 \%$ significance level (see: Table 6). Based on the results, it is possible to identify pairs of countries for which we can find arguments that the results are not spurious. Nevertheless, one should notice that the share of rejected null hypotheses in the ADF tests is lower than the assumed significance level, which might also mean that the attained results lay within the frame of test error and despite their economic sensible interpretation, they actually are econometrically spurious. The most important findings from the analysis of Table 2 - which should still be taken with some caution - are the following.

The best performer in terms of the stochastic absolute convergence is Ireland. This country exhibited stochastic convergence with 13 Western European countries (Austria, Belgium, Denmark, Finland, France, Germany, Italy, Luxembourg, Netherlands, Portugal, Spain, Sweden, and UK) and two new EU members (Hungary and Malta). The fact that the Irish economy catches up with Western Europe is logical. Ireland has strong trade and capital links with Western Europe and this is one of the sources stimulating convergence tendencies of the Irish economy toward the other Western European countries.

Some neighboring countries with close economic links also confirm the existence of stochastic convergence. This refers to both Western Europe and the new EU member states. As regards the Western European countries, convergence has been evidenced in the case of Austria and Germany 
(two neighboring countries with the same language and close links), France and Spain as well as France and UK (Spain and UK are the two neighbors of France ${ }^{3}$ ) and UK and Ireland (countries closely linked with strong historical, political, and economic ties). As for the CEE countries for which the convergence can be economically justified, we can enumerate Croatia and Slovenia (two former Yugoslav-republics) and - to a lesser extent - Croatia and Hungary (due to a common border).

Looking at the results of the absolute stochastic convergence some questions arise. Firstly, why Cyprus is the only country that exhibited stochastic convergence toward the EU28 average per capita income level? Secondly, why the pair-wise convergence was not evidenced in the case of some countries which should catch up due to evident historical, cultural, political, institutional, and economic relationships (like the Czech Republic and Slovakia, the Baltic states, Spain and Portugal, or the Scandinavian countries)?

To address these questions, it is worth to extend the analysis for conditional convergence. The lack of convergence in some evident cases may be caused by the fact that Tables 1 and 2 refer to the absolute catching-up process. Cross-sectional studies on $\beta$ convergence indicate that absolute convergence does not show the full picture of economic growth paths of the examined countries. The main argument is that the countries tend to different steady-states because the process of economic growth is multidimensional and there are numerous factors affecting the rate of economic growth that need not be equally distributed among the considered countries. It is thus worth to verify the idea of conditional stochastic convergence, which is our new concept of the analysis.

In the case of stochastic conditional convergence, we adjust the GDP time series for each country from the impact of the given country's economic growth determinants. The adjustment is made basing on the empirical model of economic growth. Initially, as described in the previous section, 10 variables were considered as economic growth determinants (and the initial GDP per capita level being the $11^{\text {th }}$ variable). On the basis of the stepwise regression, two variables (life expectancy and the number of population) were eliminated due to statistical insignificance. As a result, the final model of economic growth encompasses 9 explanatory variables (including initial GDP).

Table 3 shows the estimation results of the final model of economic growth, which is used to adjust GDP per capita time series for the analysis of conditional stochastic convergence. The model given in Table 3 is esti-

${ }^{3}$ The UK is treated as the northern neighbor due to a common maritime border with France. 
mated with the use of the Blundell and Bond (1998) GMM system estimator with the volume of GDP per capita in the current period being the explained variable. It should be emphasized, that although the functional form of the model includes the current GDP (and not its change) as the dependent variable and the lagged (initial) GDP as the independent variable, it is equivalent in its functional form to the typical beta-convergence "Barro regression" (Barro and Sala-i-Martin, 1990) as in model (5) and the transformation is due to the required instrumentalization in the panel data version of the model (see Próchniak and Witkowski 2013, 2014 for details) while the convergence parameter can be attained as the parameter on the lagged (initial) GDP per capita decreased by one.

Table 3. The model of economic growth used to adjust GDP growth rates for the stochastic conditional convergence

\begin{tabular}{lccc}
\hline Explanatory variable & Coefficient & $\boldsymbol{t}$-statistics & $\boldsymbol{p}$-value \\
\hline Initial GDP per capita & 0.9732 & 288.94 & 0.000 \\
\hline Inv & 0.0060 & 21.83 & 0.000 \\
\hline gov_cons & -0.0012 & -2.90 & 0.004 \\
\hline Open & 0.0001 & 5.18 & 0.000 \\
\hline Cab & 0.0017 & 6.41 & 0.000 \\
\hline Infl & -0.0001 & -5.19 & 0.000 \\
\hline Fert & -0.0308 & -2.89 & 0.004 \\
\hline pop_gr & -0.0065 & -5.25 & 0.000 \\
\hline pop_15_64 & -0.0037 & -4.44 & 0.000 \\
\hline Constant & 0.4315 & 7.18 & 0.000 \\
\hline
\end{tabular}

Dependent variable: GDP per capita in the current period. Estimator: Blundell and Bond GMM system estimator.

Source: own calculations.

This model is generally correct from the economic and statistical point of view. All the variables are statistically significant ( $p$-values less than 0.01 ). The coefficient standing on initial income is less than 1 , meaning that in the standard untransformed economic growth model with the change in output as the dependent variable, the coefficient on initial income would be less than zero. Hence, the model confirms the existence of cross-sectional conditional $\beta$ convergence (i.e. a negative relationship between the initial income level and the subsequent growth rate). Investments, trade openness and current account balance are the variables that have a positive impact on GDP growth while inflation, government consumption, population growth 
and fertility rate have a negative impact on the dynamics of output. These results are in line with the theoretical structural model. In the case of the share of population aging 15-64, the estimated coefficient is negative and this outcome has weaker economic background.

The results of testing the conditional stochastic convergence hypothesis, based on the adjusted GDP figures, are presented in Tables 4 and 5. Their structure is the same as that of Tables 1 and 2.

Table 4 shows the results of conditional stochastic convergence toward the EU28 average per capita income level. Now, the convergence has been evidenced for more countries than in the case of absolute convergence. In conditional terms, four countries were catching up stochastically: Croatia, Cyprus, Germany, and Ireland. As it can be seen, after introducing adjusted GDP time series, the number of converging countries increased. Among the countries that caught up, we can distinguish mainly peripheral small economies, namely Croatia, Cyprus, and Ireland. To some extent, this can be explained by the fact that small countries tend to be more open and more dependent on other economies, and it is for them easier to bridge the gap toward the average income of a given international organization. This is only our presumption, because the group of converging countries also includes Germany, i.e. the biggest EU economy. In contrast, the Germany's catching-up process may result from the fact that the biggest economies determine the reference point to which the whole group is tending and that is why they are also converging to this point.

Table 4. Results of stochastic conditional convergence toward the EU28 income level

\begin{tabular}{ll}
\hline Converging countries & $\boldsymbol{p}$-value \\
\hline Croatia & 0.01 \\
\hline Cyprus & 0.1 \\
\hline Germany & 0.1 \\
\hline Ireland & 0.05 \\
\hline
\end{tabular}

The table includes only the countries that exhibited conditional convergence, i.e. those for which adjusted GDP deviations against the EU28 average were stationary. ADF test with a single lag and a constant is used.

Source: own calculations. 
Table 5. Results of pair-wise stochastic conditional convergence

\begin{tabular}{rll} 
No. & Country & \multicolumn{1}{c}{$\begin{array}{c}\text { Countries toward which a given country } \\
\text { is converging }\end{array}$} \\
\hline 1 & Austria & Croatia, Finland, Ireland, Sweden, UK \\
\hline 2 & Belgium & Croatia, Finland, Ireland, Netherlands, Spain, UK \\
\hline 3 & Bulgaria & Estonia, Latvia, Lithuania, Poland, Slovakia \\
\hline 4 & Croatia & Austria, Belgium, Germany, Hungary, Luxembourg \\
\hline 5 & Cyprus & - \\
\hline 6 & Czech Republic & Ireland \\
\hline 7 & Denmark & Ireland \\
\hline 8 & Estonia & Bulgaria \\
\hline 9 & Finland & Austria, Belgium, Germany, Ireland, Luxembourg \\
\hline 10 & France & Ireland \\
\hline 11 & Germany & Croatia, Finland, Ireland, Malta, Sweden \\
\hline 12 & Greece & - \\
\hline 13 & Hungary & Croatia, Ireland \\
\hline & & Austria, Belgium, Czech Republic, Denmark, Finland, \\
14 & Ireland & France, Germany, Hungary, Italy, Luxembourg, Mal- \\
& & ta, Netherlands, Portugal, Slovenia, Spain, Sweden, \\
\hline 15 & Italy & UK \\
\hline 16 & Latvia & Ireland \\
\hline 17 & Bithuania & Bulgaria \\
\hline 18 & Luxembourg & Croatia, Finland, Ireland \\
\hline 19 & Malta & Germany, Ireland \\
\hline 20 & Netherlands & Belgium, Ireland \\
\hline 21 & Poland & Bulgaria \\
\hline 22 & Portugal & Ireland \\
\hline 23 & Romania & - \\
\hline 24 & Slovakia & Bulgaria \\
\hline 25 & Slovenia & Ireland \\
\hline 26 & Spain & Belgium, Ireland \\
\hline 27 & Sweden & Austria, Germany, Ireland \\
\hline 28 & UK & Austria, Belgium, Ireland \\
\hline & & \\
\hline
\end{tabular}

Notes as in Table 2.

Source: own calculations.

Table 5 indicates that the pair-wise conditional stochastic convergence inside the studied group is stronger than the absolute convergence. At the $10 \%$ significance level, $10.1 \%$ of all the pairs of countries caught up while 
in the case of absolute convergence this share stood as $8.2 \%$ (see: Table 6 ). ${ }^{4}$ The country that exhibited the strongest pair-wise convergence is again Ireland. The Ireland's per capita GDP caught up with that of the 17 countries, two more than in the case of absolute convergence: 13 Western European economies (Austria, Belgium, Denmark, Finland, France, Germany, Italy, Luxembourg, Netherlands, Portugal, Spain, Sweden, and the UK) and 4 new EU member states (the Czech Republic, Hungary, Malta, and Slovenia).

Among the Western European countries, numerous converging partners were recorded also by Germany (Austria, Croatia, Finland, Ireland, Malta, Sweden) and France (Finland, Ireland, Spain, UK). Germany and France are the two largest EU economies (according to the 2014 total GDP at both current exchange rates and purchasing power parities). It is thus likely that these countries reveal a large impact on economic growth paths of the other EU members and that is why they have relatively many converging neighbors. As regards the new EU member states, the biggest number of converging partners had some peripheral economies, namely Bulgaria (5 countries), Croatia, and Malta (both 3 countries).

Just like in the case of absolute convergence, it is also possible to find some pairs of countries exhibiting conditional catching up where the convergence has strong historical, political, and economic background. This refers to Austria and Germany, Croatia and Slovenia, France and Spain, France and UK, as well as Ireland and UK. However, some other theoretically evident cases (like the Baltics or the Scandinavian countries) have not been converging in pairs.

Finally, a robustness analysis to check how the results are affected by introducing different significance levels can be performed. Table 6 shows the share of converging pairs of countries for the three significance levels: $p=0.01,0.05$, and 0.10 , while the last figure has been adopted in the main analysis in Tables 2 and 5. These $p$-values refer to the stationarity tests where the null hypothesis assumes that both time series are non-stationary, that is they are not converging. Hence, the confirmation of convergence requires the rejection of the null hypothesis. The lower the $p$-value, the lower number of rejected null hypotheses, and the lower number of confirmed pairs of converging countries. Indeed, under the basic $p$-value of $0.10,8-10 \%$ of total examined pairs of countries exhibited stochastic convergence. At the $p$-value of 0.05 , the share of converging countries falls to

\footnotetext{
${ }^{4}$ Theoretically, the pairs showing absolute convergence should also reveal conditional convergence. However, when examining empirical data for the real economies such a situation need not hold due to, inter alia, the nature and assumptions of quantitative methods in macroeconomic modelling.
} 
$6-7 \%$, while at $p=0.01$ it falls to $4-5 \%$. That means that in most cases, except the low 0.01 significance level, the rate of rejection in the tests does not differ much from the assumed level of significance. Following the rationale of Pesaran (2007), such a result in asymptotic conditions would suggest no converging tendencies. The number of time periods in the sample is quite far from the number that would allow us to treat the conditions as asymptotic, nevertheless, all in all we should admit a failure to find any well palpable converging tendencies.

Table 6. Robustness tests: the share of converging pairs of countries at different significance levels

\begin{tabular}{ccc}
\hline $\boldsymbol{p}$-value & $\begin{array}{c}\text { Pair-wise absolute } \\
\text { stochastic convergence }\end{array}$ & $\begin{array}{c}\text { Pair-wise conditional } \\
\text { stochastic convergence }\end{array}$ \\
\hline 0.01 & $4.5 \%$ & $5.0 \%$ \\
\hline 0.05 & $6.3 \%$ & $7.1 \%$ \\
\hline 0.10 & $8.2 \%$ & $10.1 \%$ \\
\hline
\end{tabular}

The total number of different pairs is $(28 \times 28-28) / 2=378$. ADF test with a single lag and a constant is used.

Source: own calculations.

Summing up, our analysis shows that the process of stochastic convergence in the EU countries is not as widespread as the cross-sectional studies on $\beta$ or $\sigma$ convergence indicate. Even if we extend the analysis to examine conditional stochastic convergence (the original approach proposed by the authors of this study), the number of converging economies or pairs of countries rises but not as much as it could be expected from the crosssectional studies. These results also confirm the theoretical Bernard's and Durlauf's (1996) view that time series tests are based on a stricter notion of convergence than cross-section tests.

This analysis gives new insights into the nature of economic growth paths of the examined countries. The results indicate that our concept of conditional stochastic convergence is a good idea. It shows a broader picture of economic growth tendencies than the absolute convergence hypothesis and it has been worth to examine it. However, the methods of analyzing conditional stochastic convergence require further theoretical developments and empirical applications to check the robustness of the results. 


\section{Conclusions}

The study examines the concept of stochastic convergence in the EU28 countries over the 1994-2013 period. The stochastic convergence means that the expected value of future differences between the GDP per capita levels in different countries is zero in the infinite time horizon. In the paper, the convergence of individual countries' GDP per capita toward the EU28 average per capita income level and the pair-wise convergence between the GDP of individual countries are both analyzed. In addition to the standard Bernard's \& Durlauf's (1995) and Pesaran's (2007) approach, we introduce our own concept of conditional stochastic convergence which is based on adjusted GDP per capita series to account for the impact of the other growth factors on GDP. To test for stationarity of the series of differences between the GDP of a considered country and mean GDP of the whole group as well as differences of the GDP of the two countries, ADF tests are used.

The analysis shows that the process of stochastic convergence in the EU countries is not as widespread as the cross-sectional studies on $\beta$ or $\sigma$ convergence indicate. Even if we extend the analysis to examine conditional stochastic convergence, the number of converging economies toward the EU28 group's mean GDP rises from 1 to 4 and the share of converging pairs of countries rises from $8.2 \%$ to $10.1 \%$; this is still not as much as it could be expected from the cross-sectional studies.

It should be noticed that the empirical conclusions in this type of research rely strongly on the validity of the tests used. It thus seems natural to consider, as an extension, the use of different tests of stationarity - or directly the tests of co-integration - in the procedure. Another problem is the introduction of structural breaks which could be observed, for example, at the time of the recent financial crisis. Finally, given the conclusion of very doubtful convergence processes throughout EU, possibly some convergence clubs should be considered. We leave the above issues for future research.

\section{References}

Abreu, M., de Groot H. \& Florax, R. (2005). A Meta-Analysis of $\beta$-Convergence: The Legendary 2\%. Journal of Economic Surveys, 19(3). http://dx.doi.org/10.1111/j.0950-0804.2005.00253.x.

Barro, R.J., \& Sala-i-Martin, X. (1990). Economic Growth and Convergence Across the United States. National Bureau of Economic Research Working Paper, 3419 . 
Barro, R.J., \& Sala-i-Martin, X. (2003). Economic Growth. Cambridge - London: The MIT Press.

Bernard, A. B., \& Durlauf, S. N. (1995). Convergence in International Output. Journal of Applied Econometrics, 10(2). http://dx.doi.org/10.1002/ jae.3950100202.

Bernard, A. B., \& Durlauf, S. N. (1996). Interpreting Tests of the Convergence Hypothesis. Journal of Econometrics, 71(1-2). http://dx.doi.org/10.1016/03044076(94)01699-2.

Blundell, R., \& Bond, S. (1998). Initial Conditions and Moment Restrictions in Dynamic Panel Data Models. Journal of Econometrics, 87(1). http://dx.doi.org/10.1016/S0304-4076(98)00009-8.

Christopoulos, D. K., \& León-Ledesma, M. A. (2008). Time-series Output Convergence Tests and Stationary Covariates. Economics Letters, 101(3). http://dx.doi.org/10.1016/j.econlet.2008.09.009.

Cunado, J. (2011). Structural Breaks and Real Convergence in OPEC Countries. Journal of Applied Economics, 14(1). http://dx.doi.org/10.1016/S15140326(11)60007-X.

Cuñado, J., \& Pérez de Gracia, F. (2006). Real Convergence in Africa in the Second-half of the 20th Century. Journal of Economics and Business, 58(2). http://dx.doi.org/10.1016/j.jeconbus.2005.07.002.

Evans, P., \& Kim, J. U. (2011). Stochastic Convergence of the Catch-up Rate and Multiple Structural Breaks in Asian Countries. Economics Letters, 111(3). http://dx.doi.org/10.1016/j.econlet.2011.02.012.

Kane, R. (2001). Investigating Convergence of the U.S. Regions: A Time-Series Analysis. U.S. Department of Commerce, Bureau of Economic Analysis Working Paper, 2001-02.

Lau, C. K. M. (2010). New Evidence about Regional Income Divergence in China. China Economic Review, 21(2). http://dx.doi.org/10.1016/j.chieco.2010.01.003.

Le Pen, Y. (2011). A Pair-wise Approach to Output Convergence between European Regions. Economic Modelling, 28(3). http://dx.doi.org/10.1016/j.eco nmod.2010.11.006.

Mankiw, N.G., Romer D. \& Weil, D.N. (1992). A Contribution to the Empirics of Economic Growth. Quarterly Journal of Economics, 107(2). http://dx.doi.org/10.2307/2118477.

Matkowski, Z., Próchniak M. \& Rapacki, R. (2013). Nowe i stare kraje Unii Europejskiej: konwergencja czy dywergencja? Prace i Materiaty Instytutu Rozwoju Gospodarczego SGH, 91.

Pesaran, M. H. (2007). A Pair-wise Approach to Testing for Output and Growth Convergence. Journal of Econometrics, 138(1). http://dx.doi.org/10.1016 ij.jeconom.2006.05.024. 
Próchniak, M., \& Witkowski, B. (2013). Time Stability of the Beta Convergence among EU Countries: Bayesian Model Averaging Perspective. Economic Modelling, 30. http://dx.doi.org/10.1016/j.econmod.2012.08.031.

Próchniak, M., \& Witkowski, B. (2014). On the Stability of the Catching-Up Process Among Old and New EU Member States. Implications from Bayesian Model Averaging. Eastern European Economics, 52(2). http://dx.doi.org/10.2753/EEE0012-8775520201. 